\title{
PERCEPCIONES DEL CAMBIO CLIMÁTICO EN LA ISLA DE CHILOÉ: DESAFÍOS PARA LA GOBERNANZA LOCAL
}

\author{
RODOLFO SAPIAINS A. ${ }^{a}$, ANA M. UGARTE C. ${ }^{a} \&$ JULIO HASBÚN M. ${ }^{b}$
}

\begin{abstract}
RESUMEN
La Isla de Chiloé, en el sur de Chile, presenta múltiples problemas asociados al uso no sustentable de recursos naturales y a condiciones sociales de desigualdad y pobreza. Este artículo explora con métodos cualitativos cómo actores claves de la Isla están percibiendo y respondiendo al cambio climático en este complejo contexto socioambiental. Los resultados muestran que el fenómeno es percibido como un problema emergente, cuyos impactos sociales y ambientales ya están ocurriendo. Ante esto se despliegan respuestas generalmente individuales, prevaleciendo las asimetrías de poder y la competencia por sobre la colaboración, coordinación e intercambio de buenas prácticas. Un sistema de gobernanza climática en la Isla demanda cambios no sólo institucionales sino también transformaciones sociales y culturales.
\end{abstract}

PALABRAS CLAVE: cambio climático, Chile, Chiloé, percepciones, gobernanza, adaptación.

\section{PERCEPTIONS OF CLIMATE CHANGE ON THE ISLAND OF CHILOÉ: CHALLENGES FOR LOCAL GOVERNANCE}

\begin{abstract}
Chiloe is an island in the south of Chile that presents multiple issues associated with the nonsustainable use of natural resources and high levels of poverty and inequality. Using qualitative methods, this article explores how keys stakeholders are perceiving and responding to climate change in such a complex social and environmental context. Results show this phenomenon is perceived as an emergent issue, whose social and environmental impacts are already happening. Generally individual responses are implemented, prevailing power asymmetries and competition over cooperation, coordination and exchange of experiences between stakeholders. A climate change governance system for the island should deal not only with institutional barriers but also promote social and cultural transformations.
\end{abstract}

KEY WORDS: climate change, Chile, Chiloé, perceptions, governance, adaptation.

a Universidad de Chile, Centro para las ciencias del clima y la resiliencia, (CR)2. $\measuredangle$ rodolfo.sapiains@gmail.com

b Symbolon consultores. 


\section{INTRODUCCIÓN}

El cambio climático es un problema político, cultural y social que desafía prácticas cotidianas y aspectos claves de las sociedades modernas, como el libre mercado y la sociedad de consumo (Gupta, 2016). En este sentido, no es sólo un problema científico-técnico que pueda ser enfrentado con soluciones tecnológicas y el trabajo de los expertos en clima, más bien representa un desafío y una oportunidad que requiere una aproximación multidisciplinaria (IPCC, 2014) que ponga de relieve tanto el estudio de la dimensión humana del fenómeno como las subjetividades involucradas.

Para Latinoamérica este fenómeno constituye uno de los desafíos más importantes de los últimos tiempos; y para Chile, en particular, se hace urgente avanzar en estrategias de adaptación y mitigación del cambio climático, considerando que el país cumple con 7 de los 9 criterios establecidos para ser considerado vulnerable a los efectos de este fenómeno: tiene áreas de borde costero de baja altura; zonas áridas, semiáridas; zonas con cobertura forestal y zonas expuestas al deterioro forestal; es un país propenso a desastres naturales; también a la sequía y la desertificación; presenta zonas urbanas con contaminación atmosférica; y zonas de ecosistemas frágiles, incluidos los sistemas montañosos (Oficina de Cambio Climático, 2014). Para entender la magnitud del problema en nuestro país, es fundamental considerar que los impactos del cambio climático están influenciados por las condiciones sociales y económicas de cada sociedad (IPCC, 2014). La vulnerabilidad climática se relaciona con la inseguridad respecto al bienestar de los individuos, los hogares o las comunidades enfrentándose a un entorno cambiante, en términos ecológicos, económicos, sociales y/o políticos, con la consecuente posibilidad de sufrir daño y una alta dificultad para recuperarse de éste (Moser, 1998; Kaztman, 1999; Wilches-Chaux, 2000; Pizarro, 2001; Vargas, 2002). Por lo tanto, la vulnerabilidad frente al cambio climático se incrementa con altos niveles de desigualdad, pobreza y con un sistema de gobernanza débil o inexistente (Hernández et al. 2015; Forero et al. 2014; Conde, 2008; Alfaro \& Ribera, 2008).

Diversos estudios muestran que en Latinoamérica existe gran preocupación de la ciudadanía por los impactos que el cambio climático está teniendo o puede llegar a tener, en particular sobre el sector agrícola y la soberanía alimentaria; el acceso y suministro de agua; y la salud de las comunidades más vulnerables, especialmente en sectores rurales e indígenas (Conde, 2008; Pérez, 2008; Ulloa, 2008; Yana, 2008; Otagri et al. 2008; Alfaro \& Ribera, 2008). Estos estudios hacen especial hincapié en la falta de espacios de participación efectivos en la mayoría de los países de la región (Otagri et al. 2008; Ulloa, 2008; Hardoy \& Pandiella, 2009; Hardoy \& Romero Lankao, 2011; Quintero-Ángel et al. 2012; Rubin \& Rossing, 2012; Audefroy, 2015) y por lo mismo en la necesidad de fortalecer las redes de apoyo y el capital social sobre el cual las personas despliegan y refuerzan sus respuestas de adaptación (Soares \& Vargas, 2012). Esto implica favorecer un mayor grado de injerencia de las comunidades más vulnerables en la toma de decisiones a nivel local y regional (Carreón et al. 2014), para desarrollar mayor resiliencia ante estos eventos, lograr un mayor impacto de las políticas públicas y un uso más efectivo de los recursos de los Estados.

Esto resulta aún más relevante considerando que, aun cuando el foco de la acción climática ha estado a nivel internacional, existe un creciente interés por sus impactos locales (Pohlmann, 2011), especialmente, por el hecho de que es en ese nivel donde en general los gobiernos cuentan con herramientas para implementar políticas climáticas, como la regulación del uso del suelo; regulaciones residenciales y comerciales; opciones de transporte y manejo de basuras; entre otras (Kousky \& Shneider, 2003). Al observar el espacio local se hace notoria la convivencia de múltiples actividades y actores sociales, políticos y administrativos, que hacen importantes esfuerzos para dirigir, controlar o gestionar el alcance de distintos bienes públicos (Kooiman, 1993; Kjaer, 2004), en lo que se ha denominado "gobernanza". Ésta refiere a las acciones, procesos, leyes, tradiciones e instituciones a través de las cuales se ejerce autoridad y se toman e implementan decisiones (Renn, 2008). Así, en el territorio local se entrecruzan variadas posiciones e intereses, que presionan por definir los problemas y sus soluciones, en un denso tejido de conexiones que hacen al Estado crecientemente poroso, cuestionando el imaginario moderno de 
la separación estado-sociedad-mercado (Mitchell, 2006). Lo anterior representa asimismo el tránsito de una concepción de la "gestión del problema", a su gobernanza, pues ésta involucra una mayor cantidad de actores, en una mirada no sólo técnicopolítica, sino también enraizada en dinámicas socioculturales locales y principios generalmente democráticos, lo que es altamente relevante al momento de enfrentar problemáticas de gran complejidad, como el cambio climático.

De este modo, es posible observar una serie de transformaciones en los procesos de configuración de las relaciones de conocimiento y poder en el espacio local, caracterizados por la coexistencia de distintos sistemas de gobernanza: (i) monocéntrica, (ii) multi-escalar, y (iii) adaptativa (Termeer et al. 2010). La gobernanza monocéntrica alude a la idea de modernidad clásica, con un Estado centralizando el poder y control en forma jerárquica hacia las regiones y municipios ("de arriba hacia abajo"). En cambio, la gobernanza multi-escalar se orienta hacia los desplazamientos del poder y control del Estado a distintas escalas: internacional, regional, municipal, comunitario, así como otros actores no estatales. La gobernanza adaptativa, por su parte, asume el cambio continuo y abrupto, caracterizado por consecuencias impredecibles. Así, un sistema social muestra alta adaptabilidad cuando los actores tienen la capacidad de reorganizarlo dentro de estados deseables, en respuesta a condiciones cambiantes y a eventos disruptivos (Folke et al. 2005).

En muchos países desarrollados, la "Gobernanza Climática" es una demanda social y organizada, en cambio, en países con menor desarrollo, el cambio climático es un fenómeno que se está introduciendo lentamente en las agendas políticas, sociales y del sector privado (Montaña, 2015), por ende, las perspectivas de afrontamiento del problema con foco en la gobernanza tienen un desarrollo incipiente. Además, para constituir Gobernanza Climática a nivel local son fundamentales tres sistemas: la ciencia climática, el financiamiento y la legislación, los cuales aún son débiles en nuestros países (Harris et al. 2016). En este contexto, las capitales de América Latina presentan distintos tipos de gobernanza, siendo Bogotá y Ciudad de México ejemplos de alto nivel de institucionalidad climática. En cambio, Santiago de Chile y Lima muestran gran fragmentación institucional y carencia de entidades específicas para liderar la temática. Para el caso chileno, existe el Departamento de Cambio Climático del Ministerio del Medio Ambiente, el cual es insuficiente para liderar el proceso, considerando sus escasos recursos, bajo nivel de visibilidad y exigibilidad.

Sin embargo, si nos situamos en el nivel local, también es relevante hacer otras distinciones. No es lo mismo el enfrentamiento del cambio climático desde un enfoque de gobernanza en sistemas locales urbanos que en sistemas locales rurales. En Latinoamérica, en las zonas rurales los problemas de relaciones de poder y patrones de desarrollo inequitativo se acentúan. Además, enfrentan una reestructuración social y económica que implica la delegación de responsabilidades de planificación, la privatización de los recursos y enfoques de gestión en red que han minado los supuestos clásicos de la academia y la política (Morrison, 2014). Esto se observa en múltiples casos a nivel internacional. Por ejemplo, en áreas rurales del Perú, se han estudiado las dinámicas de gobernanza desde la perspectiva de los procesos de aprendizaje, donde se ha constatado que tres tipos de aprendizaje, a saber, experticia técnica, narrativas orales y conocimiento experiencial, se combinan para empoderar a las comunidades rurales a actuar colectivamente (Chapple \& Montero, 2016). En este sentido, resulta fundamental abordar la problemática del cambio climático desde lo local-rural, pues las particularidades del territorio demandan una atención especial para desarrollar sistemas de gobernanza climática adecuados.

Para el caso de comunidades locales de pescadores emerge otro tipo de complejidades a tener en consideración, en un campo que está recibiendo creciente atención en regiones de Asia, África y Europa (Shaffril et al. 2017a), en tanto medios de vida dependientes de recursos naturales afectados por el cambio climático, especialmente en el sudeste asiático. En esta región, el caso de Bangladesh muestra los límites y barreras para la adaptación por parte de dichas comunidades, observando que existen distintos obstáculos: botes con baja tecnología, pronósticos del tiempo imprecisos, señales de radio pobres, falta de acceso al crédito, bajos ingresos, falta de educación, habilidades y medios de vida alternativos, 
subestimación de la ocurrencia de ciclones, coerción por parte de los capitanes y dueños de botes, esquemas de crédito desfavorables, falta de aplicación de regulaciones de pesca y leyes marítimas, así como falta de acceso a los mercados (Islam et al. 2014). En Malasia se analizaron las estrategias de adaptación de las comunidades, hallando seis: reducir los riesgos asociados con las rutinas de pesca, fortalecimiento de las relaciones sociales, gestión del conocimiento del cambio climático por parte de los pescadores, facilitación de aprendizajes y habilidades alternativas en las comunidades, involucramiento de los pescadores en la planificación de la adaptación al cambio climático y mejora del acceso a crédito (Shaffril et al. 2017b). En el caso de Indonesia se halló que sus estrategias de adaptación incluían la diversificación de actividades económicas, el aumento de aparejos de pesca, el cambio de caladero, la movilización de los miembros de la familia al trabajo y ajustes al tiempo de pesca (Mulyasari et al. 2018).

En Chile, pocas investigaciones abordan la relación cambio climático -gobernanza - localidades rurales. Para contribuir a la construcción de conocimiento en esta área, desarrollamos un estudio de caso en el Archipiélago de Chiloé ${ }^{1}$, ubicado en el sur del país. Particularmente, nos centramos en la zona de Dalcahue, parte de Chiloé central, territorio donde se consolidó la industria salmonera y donde han tenido lugar los cambios económicos, ambientales y sociales más profundos y evidentes a partir de la llegada del salmón (Montecinos, 2009). Nos enfocamos en comprender cómo los habitantes de Chiloé están percibiendo la problemática ambiental que afrontan en un contexto de cambio climático, cómo están respondiendo a estos desafíos y de qué manera las condiciones de vida de la zona y los sistemas de creencias y valores de las personas condicionan las posibilidades para enfrentarlo y desarrollar un sistema de gobernanza climática adecuado a sus necesidades.

A continuación, se contextualiza brevemente la problemática del cambio climático en Chile, luego se presenta el diseño metodológico que

1 El Archipiélago de Chiloé está formado por más de treinta islas, con una extensión de $9.181 \mathrm{~km}^{2}$ y se encuentra en la región de Los Lagos, entre los $42^{\circ}$ y $43^{\circ} \mathrm{S}$ y $75^{\circ}$ y $73^{\circ} \mathrm{O}$. Administrativamente corresponde a la provincia del mismo guió la investigación, junto con los principales resultados del análisis del caso, para finalizar discutiendo cuestiones clave que surgen del caso de estudio respecto a cambio climático y gobernanza climática.

\section{CAMBIO CLIMÁTICO: CONFLICTOS DE CONTENIDO AMBIENTAL EN CHILE}

La Tercera Encuesta Nacional de Medio Ambiente y Cambio Climático (Sapiains et al. 2017) muestra que en Chile existe un consenso respecto a que el cambio climático sí está ocurriendo (84\%) y es causado total o parcialmente por la actividad humana (89\%), a diferencia de lo que sucede en países como Estados Unidos (Leiserowitz et al. 2014) o Australia (Leviston et al. 2014). Además, en Chile el problema se asocia a altos niveles de preocupación (77,2\%), se considera que los impactos serán bastante o muy graves (89.8\%), que afectarán múltiples ámbitos de la sociedad y en un país muy poco preparado (95\%). Por otra parte, un porcentaje importante de los participantes está de acuerdo o muy de acuerdo con que los impactos del cambio climático están fuera de su control (64,5\%); aunque al mismo tiempo un alto número de encuestados expresa que hacer algo para enfrentar el cambio climático es un deber moral (89,7\%). En la misma línea, consultados respecto a la solución del cambio climático, se atribuye a las grandes empresas, los países ricos, y los gobiernos y municipalidades los mayores grados de responsabilidad. No obstante, la responsabilidad del encuestado junto a su familia y amigos es también alta (completamente responsables + bastante responsables $=60 \%$ ). Consistentemente con lo anterior, prevalece la creencia de que el Gobierno y en particular el Ministerio del Medio Ambiente son los que tienen que liderar el problema en el país. Finalmente, las cifras relacionadas con participación ciudadana son muy bajas (generalmente menos del $5 \%$ de los consultados declara haber participado en actividades relacionadas con el medio ambiente).

Complementariamente, diversos estudios

nombre y se encuentra a una distancia de 87.99 kilómetros al sur de la capital regional Puerto Montt (http://www. gobernacionchiloe.gov.cl/geografia/). 
de caso desarrollados en el país muestran que las comunidades locales perciben cambios significativos en el clima, como alteraciones en las temperaturas, lluvias y radiación solar en comunidades indígenas andinas (Feo et al. 2009; Espinosa, 2013); escasez hídrica en el Valle del Elqui (Young et al. 2010), en la región del Maule interior (Roco et al. 2014, 2015) y en la región del Biobío (Infante \& Infante, 2013); y en Punta Arenas, región de Magallanes, se percibe una disminución de nieve y escarcha, aumento de la temperatura en verano, de la radiación solar, de las lluvias, de la intensidad del viento, y del derretimiento de hielos; y cambios en las temperaturas de invierno (Novión \& Estrada, 2011). Los impactos percibidos por estas comunidades están generalmente asociados a condiciones previas de deterioro ambiental, pobreza y desigualdad que intensifican los cambios climáticos e incrementan la exposición y vulnerabilidad de dichas comunidades.

Al mismo tiempo, en el desarrollo de prácticas de adaptación se evidencian múltiples barreras que limitan o impiden su implementación. Por ejemplo, la prevalencia de prácticas individuales y aisladas asociadas a una baja percepción de control y responsabilidad sobre el problema (Feo et al. 2009; Espinosa, 2013); la falta de información y la baja percepción de riesgo inmediato ${ }^{2}$ (Rojas \& Parra, 2010; Rojas, 2012; Infante \& Infante, 2013); la percepción de fuertes barreras institucionales para la participación ciudadana (Ibíd.); y limitaciones jurídicas $e$ institucionales generalmente asociadas a críticas al código de aguas y la falta de recursos a nivel municipal y local (Young et al. 2010). En su conjunto estos estudios muestran la importancia de entender las particularidades del cambio climático en sus contextos sociales y ambientales. Por ello, resulta fundamental explorar cómo las personas perciben y responden a este fenómeno desde las creencias y valores que prevalecen en cada región del país, así como desde las condiciones locales de vida de cada comunidad enfrentándose a los nuevos escenarios climáticos.

En dicho sentido, está emergiendo una literatura de Sistemas Socio-ecológicos (SES) que, desde la teoría del lugar, busca comprender cómo las personas experimentan y gestionan el cambio

2 Lo cual es contradictorio con los datos de la encuesta nacional, pero posiblemente explicado por las características socio-ecológico (Chapin \& Knapp, 2015), pues hay prueba de las fuertes dinámicas de interacción entre lugares, percepciones de riesgo y adaptación (Quinn et al. 2018). Estas aproximaciones ponen énfasis en el sentido del lugar, es decir, los significados y apegos que las personas sienten frente a los lugares donde se desarrollan, los cuales influencian sus percepciones y las maneras en que experimentan y se comportan frente a los puntos de inflexión que están atravesando los Sistemas Socio-ecológicos en un escenario de cambio climático (Stedman, 2016). En dicha dirección, un estudio de riesgo de inundación en dos ciudades italianas halló que, en aquellos hogares en riesgo, si el apego al lugar era fuerte, entonces la relación entre percepción de riesgo y acción era débil (De Dominicis et al. 2015). Dado que las percepciones de riesgo determinan los límites sociales de la adaptación (Adger et al. 2009), su análisis permite comprender cómo son construidas en esta interacción, pues no sólo dan forma a las acciones de adaptación, sino también a las preferencias de política para una adaptación al cambio a gran escala (Leiserowitz, 2006).

Otro elemento teórico a considerar en esta discusión es el concepto de conflicto [de contenido] ambiental. El cambio climático es una problemática social de gran envergadura, ¿pero podemos considerarlo un conflicto de carácter ambiental, al menos para nuestro caso de estudio? Si consideramos que el punto clave de interpretación de los vínculos entre un grupo humano y su ambiente es el de relación, podemos afirmar que cuando una comunidad consigue estabilizar su relación con el ambiente, en cuanto a disponibilidad de recursos y condiciones de habitabilidad, logra consolidar históricamente un espacio socioambiental, caracterizado por una relación sociedad/naturaleza específica que funciona en armonía con las distintas expresiones culturales de esa sociedad, independientemente de si esta estabilización implica una relación sustentable ambientalmente o respetuosa de los equilibrios ecológicos (Folchi, 2001). En este sentido, cuando algo amenaza esta particular relación sociedad/naturaleza se produce un conflicto, el que algunos autores catalogan como "conflicto ambiental", aludiendo que

diferenciales del mundo rural y regional de los estudios citados. 
éste se origina a partir de un impacto, daño o problema ambiental que involucra a dos actores cuyos intereses respecto de dichos impactos son contrapuestos (Padilla, 1990, en Folchi, 2001). Desde esta perspectiva, no basta que un actor provoque algún deterioro ambiental para que se origine el conflicto, sino que es necesario que haya otro actor que tome conciencia de la ocurrencia de un daño ambiental en su entorno y esté dispuesto a defender o proteger el ambiente afectado. De hecho, Sabatini (1997) sostiene que estos conflictos se generan en torno al impacto ambiental o a las externalidades de grandes proyectos productivos, inmobiliarios o de infraestructura y a la acción organizada de la comunidad local para resistir estas externalidades e impactos asociados.

Sin embargo, esta visión de los conflictos es altamente ambientalista, al pretender que su foco es necesariamente valórico o ideológico (defensa del medio ambiente porque es justo), y se centra sólo en la conflictividad ambiental, omitiendo problemáticas sociales, económicas, de poder o de otro tipo, que inevitablemente están presentes en los territorios. Por ello, nos parece más pertinente trabajar con el concepto de "conflictos de contenido ambiental", propuesto por Folchi (2001), que abarca la pluralidad de conflictos vinculados a la dimensión ambiental y no sólo aquellos en los que se defiende el medio ambiente. Desde esta mirada, los conflictos de contenido ambiental no son sólo aquellos que nacen de un daño ambiental, sino de cualquier proceso de transformación ambiental no consensual sobre el ambiente, independientemente de su valoración. Un conflicto de contenido ambiental se produce cuando se tensiona la estabilidad histórica conseguida entre una comunidad y su hábitat, ya sea como consecuencia de la acción de algún agente extraño que altera las relaciones

3 El fenómeno conocido como "marea roja" en Chile corresponde a floraciones de algas nocivas (FAN) que han afectado a las costas del sur del país durante las últimas cuatro décadas, restringiéndose a la región de Magallanes; sin embargo, hace unos años atrás se ha expandido hacia las regiones de Aysén y Los Lagos (Universidad de Los Lagos, 2016). Además se ha intensificado, tanto en términos del área costera afectada como de las especies tóxicas detectadas. Particularmente en la región de Los Lagos, a la cual pertenece la Isla de Chiloé, a fines de preexistentes entre una comunidad y su ambiente; o cuando la misma comunidad decide modificar su vinculación con el ambiente, afectando los intereses de alguna otra parte.

Lo que se produce es un conflicto de intereses entre dos o más actores "en" un medio ambiente específico, no "por" ese medio ambiente; que es lo que sucede en nuestro caso de estudio, donde el conflicto existente refleja la disputa de intereses entre distintos actores por la gestión del territorio y la dificultad de lograr un acuerdo entre ellos. El Archipiélago de Chiloé presenta numerosos problemas asociados al cambio climático, a los impactos de la industria salmonera, la sobrepesca, la deforestación del bosque nativo y la extracción sin restricciones de ciertos recursos naturales locales (CONAF \& UACH, 2013; Sepúlveda et al. 2013; Gajardo et al. 2016; Román et al. 2016; Tucca et al. 2016); así como una compleja realidad social y económica en un contexto de aislamiento político y creciente malestar ciudadano estimulado por los últimos episodios de marea roja ${ }^{3}$. En las últimas décadas, Chiloé pasó rápidamente de una sociedad rural-tradicional, basada en sistemas de subsistencia e intercambio y centrada en actividades como la agricultura, pesca, recolección en el borde costero y forestal para leña, a una sociedad semi urbana-modernizada, presionada por un crecimiento descontrolado y desregulado, con gran carga de actividades productivas que han cambiado la estructura de los ingresos familiares implicados y han proletarizado a la población (Barton et al. 2013). Como se observa, las condiciones que desencadenan el conflicto son diversas, así como la forma que adopta la movilización ciudadana, la que ha dado paso a la emergencia de nuevas relaciones de poder asociadas al uso de la naturaleza en el Archipiélago. Consideramos que el estudio de la dimensión humana del conflicto de contenido ambiental, con foco en el cambio climático, en

febrero de 2016 comenzó a manifestarse una floración del dinoflagelado tóxico Alexandrium catenella, observándose altas mortalidades de moluscos bivalvos, aves y peces (Ibíd.). Como consecuencia de la intensidad y extensión del fenómeno, y la coocurrencia de las floraciones nocivas en la costa de Chiloé con el vertimiento de 9.000 toneladas de salmones muertos (procedentes de la industria salmonera) en altamar, se generaron protestas sociales y ambientales en Chiloé que luego se extenderían a otras localidades de la región de Los Lagos (Greenpeace, 2016). 
comunidades del Archipiélago de Chiloé resulta muy relevante, dado que diversos estudios han mostrado que la zona es altamente vulnerable a los efectos de este fenómeno considerando la dependencia del Archipiélago de los recursos marinos y de la actividad agrícola, como así también teniendo en cuenta las presiones sociales y ambientales ya existentes.

\section{DISEÑO METODOLÓGICO}

Esta investigación se realizó mediante metodología cualitativa, la cual busca comprender la complejidad y dinámica de la realidad social desde la propia perspectiva de los actores que tienen parte en ella, indagando en la forma en que éstos experimentan e interpretan el mundo, intentando comprender los motivos y agencias que están detrás de sus acciones, en relación a sus contextos cotidianos (Taylor \& Bogdan, 1994). Desde esta metodología, conocimiento y práctica se estudian localmente (Flick, 2007), cobrando relevancia el análisis de casos concretos en su particularidad temporal y espacial; por lo tanto, esta investigación no pretende generalizar sus resultados, sino que producir conocimiento situado, que aporte a la comprensión de las percepciones, actitudes y acciones que tienen los habitantes de Chiloé sobre la conflictividad ambiental que enfrentan.

En este marco, este estudio tiene un carácter exploratorio y descriptivo (Hernández et al. 1998). Exploratorio, pues representa uno de los primeros acercamientos al fenómeno de la conflictividad ambiental en Chiloé desde una perspectiva de gobernanza local; y descriptivo, dado que se buscó especificar las principales características del tema en cuestión, con énfasis en la subjetividad de los actores sociales (Ibíd.), construyendo así categorías analíticas que permitan comprender las particularidades del objeto de estudio.

En cuanto a la muestra con la que se trabajó, cabe destacar que desde la metodología cualitativa se busca que los sujetos en cuestión posean ciertas posiciones discursivas diferenciadas en la estructura social (Mejía, 2000); por ende, la representatividad de la muestra no habla de una representación proporcional, sino de una representación de posiciones. Se utilizó entonces un muestreo estratégico, seleccionando tipos discursivos, los cuales se elaboraron a partir de atributos de identidad, características que poseen los sujetos que permiten la mejor aproximación posible al objeto de estudio. En este caso se decidió trabajar con representantes del sector pesca artesanal, recolección de orilla y acuicultura de la comuna de Dalcahue, por ser los sectores productivos más afectados por la conflictividad de contenido ambiental en Chiloé, particularmente por el episodio de marea roja que tuvo lugar en la isla entre febrero y marzo de 2016, el que además afectó principalmente a la comuna de Dalcahue. Dado esto, la muestra estuvo compuesta por 21 personas (19 hombres y 2 mujeres). Cabe señalar que la región de Los Lagos, donde se sitúa Chiloé, ha figurado como una de las más productivas, registrando además, la mayor cantidad de pescadores y embarcaciones inscritas, así como de acuicultores y recolectores de orilla. Adicionalmente, un alto porcentaje de los pescadores, recolectores y acuicultores se encuentran asociados bajo figuras como el sindicato, la asociación gremial, cooperativas y en algunos casos, sociedades económicas de responsabilidad limitada o anónima, que a su vez se asocian en organizaciones de carácter nacional (www.subpesca.cl).

Para producir la información requerida se utilizaron como técnicas la entrevista semiestructurada y la observación participante. La entrevista semi-estructurada es un tipo de interacción conversacional donde la producción de información se orienta a partir de preguntas abiertas y relativamente libres (Gaínza, 2006), vinculadas directamente con los temas a investigar, lo que si bien da el espacio y libertad suficiente al informante para definir el contenido, estructura y acota el discurso en relación al tema de interés investigativo. Esta técnica permitió producir información pragmática, que se relaciona tanto con las conductas como con los significados relacionados a las prácticas (Merlinsky, 2006). Las principales temáticas que se abordaron con este instrumento fueron las percepciones, creencias y actitudes de los habitantes de Chiloé en torno a la conflictividad ambiental general presente en la Isla, con énfasis en el cambio climático; y las estrategias de adaptación que han realizado para enfrentar estas problemáticas, indagando especialmente 
Tabla 1. Muestra de actores entrevistados.

\begin{tabular}{ll}
\hline E1 & Hombre, Recolector \\
E2 & Hombre, Mitilicultor \\
E3 & Hombre, Representante Gobierno Local, Departamento de Medio Ambiente \\
E4 & Hombre, Pescador artesanal \\
E5 & Hombre, Pescador artesanal \\
E6 & Hombre, Mitilicultor \\
E7 & Hombre, Pescador artesanal \\
E8 & Hombre, Recolector \\
E9 & Hombre, Mitilicultor \\
E10 & Hombre, Buzo-Recolector \\
E11 & Hombre, Pescador artesanal \\
E12 & Mujer, Recolectora de orilla \\
\hline
\end{tabular}

Fuente: elaboración propia.

en acciones colectivas. Todas las entrevistas se realizaron presencialmente durante el mes de noviembre de 2016 y tuvieron aproximadamente 60 minutos de duración. Se aplicaron a 12 personas (11 hombres y 1 mujer), representantes de los sectores de pesca artesanal, acuicultura (mitilicultura) y recolección de orilla; y del sector gobierno local (municipio). Fueron registradas en audio previo consentimiento informado de los participantes, y transcritas para su análisis (Tabla $1)$.

Por su parte, la observación participante es una técnica que permite al investigador describir sistemáticamente eventos, comportamientos $y$ acciones en el escenario social mismo donde se producen(Marshall \& Rossman, 1989), participando de las actividades cotidianas que realizan los actores (Schensul et al. 1999); permitiendo incrementar la validez del estudio al ayudar al investigador a tener una mejor comprensión del contexto y el fenómeno en cuestión (DeWalt \& DeWalt, 2002). Para esta investigación, se utilizó la observación participante para ir más allá del discurso de algunos de los actores que sostenían participar de movimientos sociales organizados, en este caso, de una Mesa de Marea Roja, lo que permitió otorgar énfasis a la dinámica relacional entre los sujetos y al sentido que le otorgan a sus acciones. Puntualmente, se participó de una reunión de la Mesa de Marea Roja de Dalcahue, que en dicha ocasión contó con la presencia de 9 personas, la que tuvo lugar el 28 de octubre de 2016 y duró aproximadamente
3 horas. En esta mesa se discutieron temas respecto a cómo comunicarse con autoridades regionales (Senador), contactos con empresas de salmonicultura, así como distintos problemas de los pescadores y buzos. Esta reunión fue grabada en audio (con consentimiento de los participantes) y posteriormente transcrita para su análisis.

Para analizar la información producida se utilizó la técnica de análisis de contenido, conjunto de procedimientos interpretativos de productos comunicativos (mensajes, textos o discursos) que buscan hacer emerger el sentido latente que procede de las prácticas sociales y cognitivas que subyace a los actos comunicativos concretos, yendo más allá de la superficie material del texto (Piñuel, 2002). $\mathrm{El}$ análisis de contenido tiene por objetivo indagar sobre lo escondido, lo latente, lo no aparente y lo potencial de todo mensaje (Bardin, 1996), lo cual es posible sólo si tal texto se abre a las condiciones contextuales del producto comunicativo, es decir, a las circunstancias psicológicas, sociales, culturales e históricas de producción y de recepción de las expresiones comunicativas con que aparece (Piñuel, 2002). En esta investigación, primero se codificó la información disponible, fragmentando el discurso en función de su significación, condensando la información en unidades analizables que permitieran construir, posteriormente, categorías analíticas (Coffey \& Atkinson, 2005), las que se obtuvieron reagrupando todos los códigos que compartían un mismo significado, es decir, que describían similarmente la esencia de las experiencias narradas 
(Bardin, 1996). De este proceso emergieron seis categorías analíticas. Finalmente, se construyeron dos esquemas interpretativos a partir de la lectura relacional de las categorías, para explicar mediante hipótesis teóricas los elementos centrales del discurso de los sujetos (Andréu, 2000).

\section{RESULTADOS}

Como se mencionó anteriormente, en primer lugar, los resultados de esta investigación fueron organizados en seis categorías analíticas, las que se detallan a continuación:

\section{Problemática socioambiental}

Esta categoría hace alusión a los conflictos de contenido ambiental que afectan con mayor intensidad a la Isla de Chiloé en general y a la comuna de Dalcahue en particular. Estos conflictos se han transformado en una problemática para sus habitantes en tanto tienen efectos negativos sobre su calidad de vida, aumentan su vulnerabilidad social y tensionan las relaciones ciudadanía gobierno local/central, siendo además situaciones de difícil solución.

Los principales conflictos identificados son: (1) Contaminación del mar, relacionado con la presencia de la industria salmonera en la Isla, principalmente por los alimentos y medicamentos con los que se trata a los salmones, quedando sus restos en el fondo marino; con desechos de combustibles fósiles en el mar, generalmente petróleo sobrante que las embarcaciones lanzan al mar; y con la existencia de altas concentraciones de basura en las playas. Para los entrevistados este tipo de contaminación tiene impactos altamente negativos para su supervivencia, pues merma el crecimiento y desarrollo de varias especies, disminuyendo la disponibilidad de recursos marinos tanto para uso doméstico como productivo: También se ve por las salmoneras mucho veneno que han tirado, es un tema grave. El veneno que bota la salmonera pa' matar los piojos del

4 Las turberas prestan importantes servicios ecosistémicos: protegen la biodiversidad, almacenan agua dulce y acumulan carbono, entre muchos otros (RAMSAR, 2002). En Chiloé, tanto turberas de origen glaciar como aquellas de origen antrópico, están siendo intensamente explotadas; se extrae salmón es lo que ha terminado con las especies, muchos peces han desaparecido. También tiene impacto en las playas, mata las algas, queda muy poco, consecuencia directa de la salmonera (E7, P1). (2) Escasez hídrica, principalmente por disminución de las precipitaciones en el territorio, afectando la disponibilidad de agua para uso domiciliario y agrícola. (3) Monocultivos de pino y eucaliptus, especies con las que se han reemplazado zonas de bosque nativo, que consumen gran cantidad de agua para su mantención y afectan la biodiversidad. (4) Y sobreexplotación general de los recursos naturales, principalmente del bosque, para la obtención de leña; del mar, por la pesca de arrastre y las salmoneras; y de la turbera sphagnum o "pompón"4, que se utiliza como aislante térmico y como filtro, entre otros.

\section{Cambio climático}

Para los entrevistados el cambio climático es causado mayoritariamente por la actividad humana, siendo el consumismo uno de los ejes centrales del problema. Se percibe como un fenómeno apremiante de difícil solución, y transversal a diferentes áreas de la vida. Los principales impactos observados del cambio climático se valoran negativamente y se relacionan con la pérdida de fuentes laborales, particularmente las vinculadas con recursos marinos, por la migración de especies, y con los cultivos, los que han cambiado. A nivel de producción marina y agrícola a mediana y gran escala también se observan impactos negativos, pues cambian los plazos de producción y el negocio se vuelve impredecible, por ende, no se pueden comprometer ventas a largo plazo:

Para mí el cambio climático es un cambio de vida, en el tema en el que estamos involucrados nosotros los de la piscicultura. Es un tema que no se puede calcular, no se pueden medir los plazos de la producción del chorito, ahora tenemos el tema que no engorda, un

principalmente su capa superficial tanto de forma artesanal como industrial, y en la gran mayoría de las ocasiones la extracción se realiza sin considerar la sostenibilidad del recurso (Díaz, 2008). 
tremendo desorden de la naturaleza. No se puede hacer un compromiso de ventas, de entregas a una empresa, de hacer un presupuesto para su bolsillo, o sea le cambió la vida totalmente, nos tienen en una inmensa incertidumbre (E6, P1).

Además de estos impactos, se observan otros cambios globales, como el aumento de la temperatura atmosférica y de la temperatura del mar; la disminución de la frecuencia de precipitaciones; cambios en las estaciones del año, perdiéndose los límites entre ellas; cambios en las mareas, las que actualmente suben o bajan con mayor intensidad; $y$ alteraciones en los ciclos naturales de las especies y en su movilidad. Así, los entrevistados manifiestan que hoy han aparecido en la Isla especies marinas que antes no existían, como el atún.

Responsabilidades causando y solucionando las problemáticas socioambientales

Se identifican diferentes actores sociales con diversas responsabilidades, tanto causando como solucionando la problemática socioambiental. Por una parte, como responsables directos aparecen las grandes empresas y el gobierno central. Los empresarios, porque no cumplen con las normativas ambientales vigentes $e$ intentan obtener una mayor producción y ganancias a menores costos de inversión, destruyendo los recursos naturales. $Y$ el gobierno central, en tanto permite que estas situaciones sucedan, al no fiscalizar adecuadamente a las empresas se transforman en cómplices de la devastación:

Insisto que son las mismas autoridades de gobierno los responsables de todo, que entregan tanta concesión $y$ tanta cosa por todos lados y porque hay mucha demanda y cómo vamos a demandarle tanta especie al mar (...) entregaron tanta concesión que por eso está pasando lo que pasa (E1, P27-32).

Por otra parte, como actores directamente implicados en las soluciones se menciona a los científicos, quienes si bien son evaluados positivamente en términos de su experiencia y capacidad de contribución a la sensibilización y divulgación, son evaluados negativamente precisamente porque no utilizan estas capacidades para comunicar e informar a la población general: la ciencia aparece desconectada y ajena, y muchas veces como poco confiable.

También se considera como responsables directos de las soluciones al gobierno central y local; el primero se reconoce como relevante porque tiene poder de incidir sobre leyes y normativas ambientales, y posee recursos económicos para financiar estrategias de adaptación y mitigación. Dentro de las acciones que se consideran como prioritarias y de exclusiva responsabilidad del gobierno central se encuentran el apoyo a los gobiernos regionales y locales para construir planes de adaptación, el fomento productivo en zonas más vulnerables, y crear fondos específicos para investigación. En cuanto al gobierno local, se sostiene que si bien su rango de acción es relativamente limitado, asociado principalmente al manejo de residuos, debería poder fiscalizar la acción de las empresas en el territorio, y además debería promover la sensibilización ambiental en la población general.

Finalmente, se señala que todos los ciudadanos son responsables de la solución a estas problemáticas, sin embargo, los discursos no aluden a acciones concretas ni a roles específicos para los ciudadanos.

\section{Estrategias de adaptación ante la problemática ambiental}

Las estrategias que señalan los sujetos para enfrentar la problemática ambiental pueden clasificarse en cuatro grupos: (1) Estrategias legales, que refieren principalmente a regularizar concesiones marítimas e indígenas, y a fiscalizar frecuentemente la actividad productiva, protegiendo los recursos naturales; (2) Estrategias de innovación y diversificación productiva, que amplíen las oportunidades laborales mediante la diversificación de las áreas productivas, aprovechando la riqueza en biodiversidad que tiene la Isla, pero de manera sustentable, que implique una menor explotación de los recursos y posibilite su recuperación; asimismo, innovar económicamente desarrollando otros sectores, como el turismo; (3) Estrategias educativas, 
que remiten a desarrollar más investigación sobre las problemáticas ambientales, con la consecuente difusión del conocimiento que se produzca; y a crear mayor conciencia ambiental en la población, sensibilizando sobre la importancia de preservar el planeta para las generaciones futuras; (4) y Estrategias específicas de Adaptación y Mitigación a nivel doméstico y a nivel productivo, como innovaciones en los cultivos, para mantener la humedad, para regar con menos agua, entre otras.

\section{Barreras para la adaptación}

el enfrentamiento de las problemáticas socioambientales se pueden agrupar en barreras psicológicas y barreras estructurales. Dentro de las primeras se encuentran: desesperanza, pues los sujetos se ven a sí mismos como poco capaces de realizar cambios, sienten que necesitan ayuda de personas con influencia política y/o económica, y como no la tienen, creen que la situación no cambiará, sino que empeorará:

Si no tenemos ayuda de los más poderosos cómo nos vamos a preparar (...) sí, hay organizaciones, pero qué sacamos con hablar y hablar si nadie nos va a escuchar (E1, P46-51); distancia temporal, perciben el cambio climático como un fenómeno lejano en el tiempo, que aún no es tan grave; tragedia de los comunes, los sujetos están principalmente motivados a actuar por intereses personales y de manera individual, destruyendo recursos que podrían ser compartidos, y aunque no les conviene esta situación no pueden evitar hacerlo porque creen que todos actúan igual; desconfianza hacia la ciencia dada su poca capacidad de socializar el conocimiento que produce; cultura consumista e individualista; falta de información sobre los impactos locales de la problemática socioambiental; poca conciencia ambiental; falta de recursos materiales, que les hace sentir en desventaja para implementar acciones; hábitos laborales contaminantes; y dificultad para proyectarse a futuro, para pensar en las próximas generaciones.
En cuanto a barreras estructurales, se mencionan las siguientes: desigualdad en la distribución y manejo de los recursos del territorio: El pescador artesanal no puede pescar, porque no hay, porque los grandes se lo llevan todo, la gente sale a pescar y no hay pesca (...) se lo llevaron todo, para ellos no hay leyes, si la ley es para los pobres como uno no más (E1, P2025); existencia de un modelo socioeconómico neoliberal y extractivista; aislamiento geográfico de la Isla de Chiloé respecto del resto del país, lo que invisibiliza a nivel nacional las problemáticas de este sector; falta de organismos fiscalizadores de la actividad industrial; planificaciones territoriales que no se realizan con participación activa de los habitantes del territorio; leyes y normativas que benefician principalmente a las grandes empresas; y alta dependencia de los recursos naturales para la sobrevivencia, siendo la actividad pesquera y recolectora la principal fuente de sustento para la mayor parte de sus habitantes:

Es supervivencia, la mayoría de la gente de la Isla trabaja mariscando $y$ ellos ahúman el marisco y lo vienen a vender acá a la feria o el día domingo y ese es el sustento que tienen ellos, es su vida, conoci mujeres que se levantan a las 6 de la mañana cuando baja la marea para sacar sus mariscos con canastillo. Es sacrificado, ellos trabajan en el campo igual, pero no les da tanto para sobrevivir (E4, P52).

\section{Dificultades para la participación}

Las principales dificultades que los sujetos reconocen para la participación son: cultura asistencialista, las personas en general están acostumbradas a esperar que el gobierno realice acciones para solucionar problemáticas en todo ámbito:

Ellos (el gobierno) están a cargo de hacer las cosas bien, de que tengas salud, estudio, que todo es una responsabilidad, no pueden desligarse, deberían hacernos charlas, estamos como 
huérfanos, no sabemos qué va a suceder, no sólo como chilotes, en el país entero estamos de brazos cruzados (E9, P6); intereses egoístas de orden económico, las personas generalmente no participan si un problema no les afecta económicamente; autoritarismo en todos los niveles sociales, que disminuye la motivación por participar de quienes prefieren estructuras más horizontales de acción social; individualismo y poca solidaridad con los pares; escasa comunicación entre vecinos; miedo a involucrarse en acciones de protesta, como marchas, tomas de establecimientos, corte de calles, entre otras; externalización de responsabilidad, culpando a los demás del deterioro ambiental, sin hacerse cargo de la cuota personal; poca confianza en los líderes sociales, se piensa que tienen intereses personales y no colectivos; idea de la comunidad perdida, en tanto se cree que antes las personas tenían vínculos más cercanos y solidarios, actuando colectivamente ante las problemáticas $\mathrm{y}$ apoyándose en las dificultades, lo que no sucedería actualmente.

Posteriormente, estas categorías fueron reorganizadas en dos esquemas interpretativos, que relacionan sus contenidos y explican en profundidad la temática de estudio.

\section{"Un tema de expertos"}

La Fig. 1 ilustra una primera forma de articular las relaciones entre las categorías identificadas previamente y la dinámica del fenómeno estudiado. Los resultados sugieren que para estos participantes el cambio climático constituye tanto un problema emergente como un factor de contexto que complejiza la ya difícil situación social y ambiental de la Isla. Al igual que para otras comunidades rurales del país (Espinosa, 2013; Infante \& Infante, 2013; Roco et al. 2015) y consistente con los resultados de la ENMACC 2017, se trata de un fenómeno conocido con impactos que ya son percibidos por la población. Notablemente se describen cambios significativos en los ecosistemas de la zona incluyendo alteraciones en el comportamiento de ciertas especies marinas y en los tiempos de producción de la mitilicultura. Adicionalmente, el cambio climático se configura como un factor que incrementa la vulnerabilidad social y ambiental de la Isla, al intensificar los impactos de problemas ya existentes como la contaminación y sobreexplotación del mar, la escasez hídrica y la pérdida de bosque nativo por el efecto de los monocultivos, y la extracción no regulada de recursos naturales como el pompón. En este sentido, las percepciones de los participantes de este estudio son consistentes con el IPCC (2014) en relación a que el cambio climático amplifica los impactos sociales y económicos de estos problemas, y contribuye a visualizarlos como temáticas que deben ser enfrentadas de manera prioritaria.

No obstante lo anterior, múltiples barreras intervienen entre la preocupación por la situación social y ambiental y las respuestas que se despliegan. Por una parte, barreras psicológicas $y$ estructurales emergen en el discurso de los entrevistados, principalmente relacionadas con altos niveles de desesperanza, la tragedia de los comunes, la falta de conciencia ambiental y la prevalencia de una cultura consumista. En este sentido, resulta interesante observar que estas mismas barreras para la adaptación encontradas en la Isla de Chiloé han sido identificadas en el contexto anglosajón con niveles de desarrollo y disponibilidad de recursos muy distintos (Lorenzoni et al. 2007 Aitken et al. 2011; Gifford, 2011). Por otra parte, aparecen barreras estructurales que revelan una institucionalidad que limita la participación ciudadana, que genera desconfianzas hacia las autoridades y parlamentarios y que reduce el ámbito de acción de los gobiernos locales, en un contexto legislativo que no contribuye a prevenir o enfrentar situaciones ambientales críticas; lo que va en línea con lo planteado por Fløysand et al. (2010) y Román et al. (2016), quienes en sus estudios sostienen que no ha habido suficiente claridad respecto de los mecanismos de involucramiento local en la gestión del territorio ni canales de comunicación adecuados entre los actores sociales, existiendo brechas significativas entre alcaldes y concejales, empresas salmoneras, pescadores artesanales y el gobierno central, lo que ha generado desconfianzas entre todas las partes. 


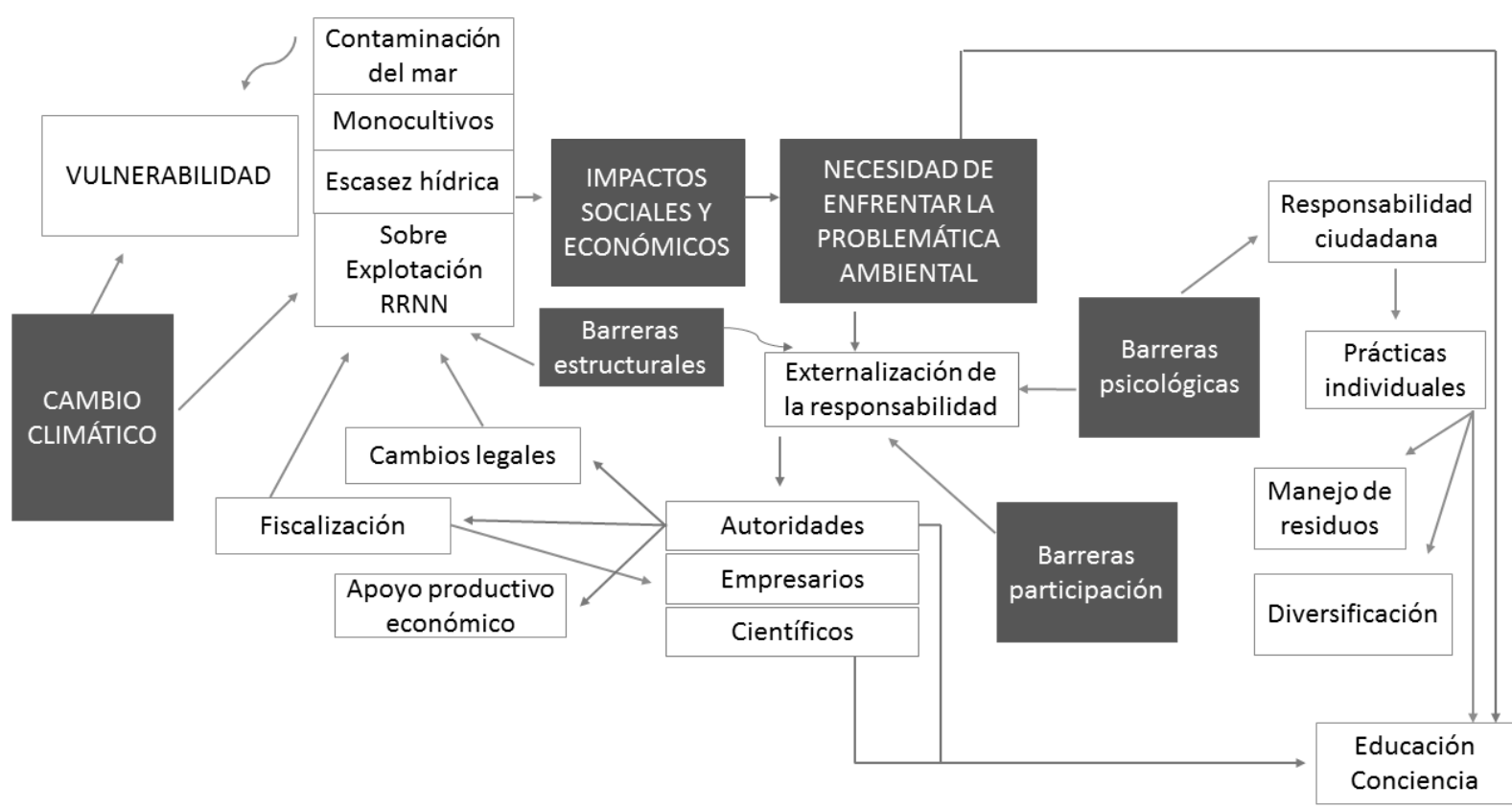

Fig. 1. Categorías analíticas emergentes. Fuente: elaboración propia.

Es decir, se constatan las mismas dificultades identificadas en otros estudios, no sólo en otras regiones del país, sino a nivel latinoamericano, en términos de la débil gobernanza climática y las dificultades para la participación ciudadana en general (Otagri et al. 2008; Ulloa, 2008; Hardoy \& Pandiella, 2009; Hardoy \& Romero Lankao, 2011; Quintero-Ángel et al. 2012; Rubin \& Rossing, 2012 Audefroy, 2015). No obstante, esta baja participación se construye también a partir de una cultura asistencialista, el individualismo y los intereses económicos personales, entre otros factores.

Todo lo anterior resulta en la externalización de las responsabilidades para enfrentar la problemática ambiental y social de la Isla. Si bien se comparte la responsabilidad en términos de las causas de estos problemas, se percibe que son principalmente las autoridades nacionales, los empresarios y los científicos los que tienen que resolverlos, debido a que esos actores son mayormente los causantes de los mismos (los empresarios), los que permiten que estos problemas ocurran y se mantengan (el gobierno), y los que poseen el conocimiento para determinar cuáles son las mejores estrategias a seguir (los científicos). Al mismo tiempo, al gobierno local solo se le atribuye una mínima responsabilidad frente a la problemática, pues sus atribuciones y poder son muy reducidos comparados con el poder ejecutivo central y sus instituciones. De este modo, se percibe que la gestión de los municipios en estas temáticas se limita a la gestión de los residuos y promover la educación ambiental.

$\mathrm{Si}$ bien esto es consistente con los resultados de la ENMACC (2017), en cuanto a la jerarquía de las responsabilidades, llama la atención que el rol de la ciudadanía se reduzca a prácticas generalmente individuales, concentradas en torno al manejo de residuos domiciliares o en el trabajo, a buscar maneras de diversificar las fuentes laborales personales, por ejemplo, invirtiendo en turismo, y a promover cambios actitudinales y conductuales en los espacios personales y laborales. La participación y organización comunitaria no aparece significativamente en el discurso de los participantes. En general todo esto es consistente con los resultados nacionales referidos al bajo nivel de participación política en actividades ambientales.

En sintesis, para los participantes de este estudio la solución de estos problemas pasa principalmente por una intervención desde arriba hacia abajo, con un foco claro en cambios legislativos, acabar con la corrupción en las 
fiscalizaciones y con la entrega de apoyo económico a las comunidades desde el gobierno central. No resulta claro que exista un rol más activo de la ciudadanía o de las comunidades locales, ni que de esa manera se puedan implementar soluciones más eficaces, no sólo para enfrentar el cambio climático, sino la complejidad social y ambiental que convive en la Isla a partir de lo planteado por los entrevistados. Todo lo anterior evidencia que para el desarrollo de un sistema de gobernanza climática en la zona, se deben abordar no sólo barreras estructurales, generalmente institucionales o legales, sino que además aquellas barreras psicológicas y estructurales que operan a nivel individual y comunitario.

"Narrativas locales del cambio climático: imaginarios de la des-gobernanza"

La Fig. 2 presenta una segunda lectura relacional e interpretativa de las categorías analíticas, haciendo énfasis en los distintos actores involucrados en las dinámicas de gobernanza del territorio. La confluencia de actores multi-escala en Dalcahue permite una aproximación a los imaginarios que realizan los locales respecto a las posiciones frente al cambio climático, tanto respecto a sí mismos, como a los demás. El escenario en que los actores relatan sus percepciones ha sido caracterizado como la "fallida gobernanza neoliberal del medioambiente" (Bustos-Gallardo, 2013; Román et al. 2016), cuya máxima expresión fue la crisis del virus ISA en la salmonicultura de la región de Los Lagos, y la crisis social y productiva por el incremento de la marea roja en Chiloé durante el 2016.

\section{Nosotros: falta de conciencia}

Los momentos clave de la gobernanza para el cambio climático pueden ser vistos como los siguientes: (i) comprensión, (ii) planificación y (iii) gestión (Moser \& Ekstrom, 2012). Desde este modelo, el primer momento contiene (i) la detección del problema, (ii) la búsqueda y uso del conocimiento/información, y la (iii) (re) definición del problema. Cuando los entrevistados se refieren a su comunidad, en su mayoría pescadores y mitilicultores de Dalcahue, con frecuencia lo hacen desde la narrativa "nos falta conciencia" para actuar frente al cambio climático, lo cual refieren principalmente a brechas en cultura y educación, y especialmente un reclamo por "guía" del municipio. Así, el primer momento de comprensión es donde los entrevistados auto-perciben barreras, asociadas a las distintas etapas de la búsqueda y uso de información, las cuales se verán reflejadas cuando describamos la percepción que tienen de la ciencia. Esta demanda hacia el gobierno local se ha observado para el caso de comunidades rurales, por ejemplo, en el caso de Rumania, donde se espera de él guiar a las comunidades locales, facilitar su construcción de capacidades, catalizar las interacciones entre las organizaciones comunitarias y el sector privado organizado, entre otros (Biriescu \& Babaita, 2014).

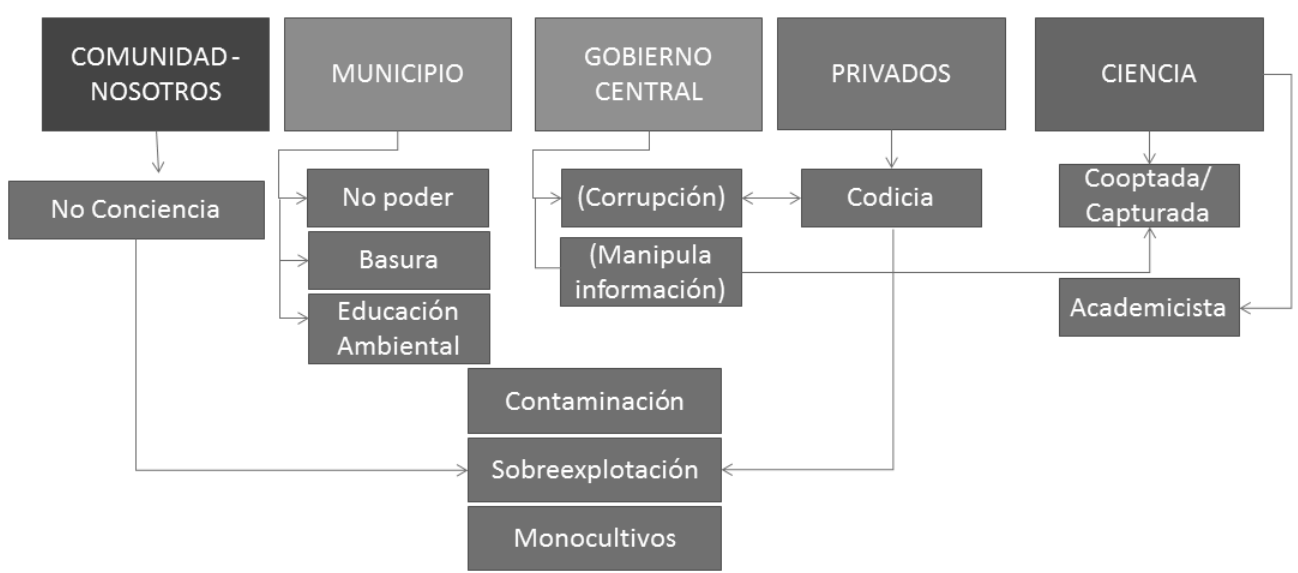

Fig. 2. Actores y narrativas transversales. Fuente: elaboración propia. 


\section{Municipio}

En relación al gobierno local, emergen tres narrativas con mayor frecuencia: (i) el no-poder del municipio, (ii) su papel en la gestión de la basura y (iii) la promoción de la educación ambiental. El nopoder se manifiesta en la percepción de que no posee las capacidades ni recursos necesarios para actuar respecto al cambio climático, a excepción del manejo de basura y crear conciencia sobre los problemas, lo que es similar a lo señalado por Fløysand et al. (2010) en su estudio sobre desarrollo económico (caso de la industria salmonera) y gobierno local en Chiloé: los municipios conocen los problemas existentes en sus comunas, pero manifiestan que no pueden actuar directamente sobre ellos, ya que enfrentan una estructura centralizada y muy jerarquizada que limita su participación y decisión sobre el uso de los recursos locales. La participación de los municipios chilenos en los ingresos y gastos respecto al gobierno central es de las más bajas de América Latina (Vial, 2016). Efectivamente, no posee los recursos de inversión para ser un actor central del desarrollo del territorio local, siendo dependiente de fondos del nivel central. Así, persiste aún mucho margen para la descentralización de las decisiones y acciones que actualmente residen en Santiago.

\section{Gobierno Central}

El gobierno central es representado narrativamente desde dos lugares: (i) cooptado por la gran empresa privada y (ii) manipulando la información presentada, por ejemplo, en el caso de la marea roja en Chiloé (2016). Esto no sorprende considerando que el Índice de Percepciones de Corrupción (Transparency International, 2016) muestra una fuerte correlación con países vulnerables al cambio climático, donde la sociedad civil no ha podido presionar para que los Estados puedan implementar mecanismos efectivos de rendición de cuentas. Si bien Chile presenta niveles relativamente bajos en este índice, esto no quiere decir que la corrupción no exista, fenómeno que induce una gobernanza ambiental sub-óptima: reduce el rigor regulatorio ambiental y socava la efectividad de los sistemas de gestión (Aidt, 2003; Dinda, 2004), porque reduce el costo social y económico de romper las reglas.

\section{Privados}

Las grandes empresas de salmonicultores y mitilicultores, muchas de ellas transnacionales europeas y estadounidenses, son discursivamente construidas bajo la narrativa de la codicia, subordinando al Estado a sus intereses. La codicia es una de las causas del cambio climático, por ejemplo, al actuar en base a una visión cortoplacista, que causa el mal uso del suelo, con la consiguiente pérdida de capacidad de secuestrar gases de efecto invernadero (Lal, 2004). Un estudio entre pequeños empresarios ingleses también mostró a la codicia como responsable del cambio climático (Williams \& Schaefer, 2013).

\section{Ciencia}

Para los entrevistados la ciencia emerge en dos narrativas: (i) capturada por los intereses políticos y (ii) excesivamente academicista. Se han reconocido cuatro modos de relación cienciapolítica: (i) cuando los políticos utilizan la ciencia para legitimar su acción, (ii) cuando los científicos instrumentalizan su conocimiento para adaptarlo a la acción política, (iii) cuando el conocimiento científico es sujeto de intereses políticos y (iv) cuando la ciencia es vista también como parte de la arena política, disputando con ésta paradigmas (Carneiro \& Da-Silva-Rosa, 2011). Vemos así que la instrumentalización ha sido analizada en ambas direcciones, aun cuando los entrevistados sólo aprecian a la ciencia como una herramienta de los políticos para legitimar su acción e inacción. Un grave problema del cambio climático es su alto nivel de complejidad, la cual incluso hace que estudiantes graduados del MIT (Massachusetts Institue of Technology) no puedan comprender los procesos científicos explicados en los reportes del Panel Intergubernamental para el Cambio Climático (IPCC, siglas en inglés), que concentran la ciencia disponible para hacer entendible el fenómeno (Sterman \& Booth-Sweeney, 2007; Sterman, 2011).

A partir de estas percepciones se puede plantear que las problemáticas ambientales identificadas en este estudio, con su conflictividad asociada, demandan soluciones que exceden los ámbitos de la gestión ambiental de expertos. Se 
evidencia que el actual sistema de gobernanza ambiental en este territorio particular no funciona de manera adecuada. Los resultados presentados sugieren que si bien se identifican múltiples actores sociales operando a distintos niveles, existe una crítica amplia hacia el desempeño del gobierno central y sus instituciones, en tanto representan el marco regulador y fiscalizador que debería anticipar y solucionar estos problemas; hacia la empresa privada que no respeta las regulaciones ambientales; hacia la comunidad científica que se percibe alejada de las comunidades locales; y hacia la misma ciudadanía que se autopercibe desde una posición asistencialista y desempoderada.

Considerando que se trata de problemáticas que ponen en riesgo los medios de vida de las comunidades locales, con un sistema inefectivo de procesamiento del conflicto, y la existencia de un marco regulatorio percibido como pro-industrial y extractivista, resulta fundamental pensar en el desarrollo de modelos de gobernanza que acojan las particularidades de este territorio. Entendiendo la gobernanza como "el proceso de conducir la sociedad y la economía a través de la acción colectiva y de acuerdo con objetivos comunes" (Torfing et al. 2012) o "los procesos interactivos a través de los cuales la sociedad y la economía son conducidas hacia objetivos colectivamente negociados" (Ansell \& Torfing, 2016), el desafío para estas localidades es imaginar formas de articulación entre los actores que les permitan enfrentar la alta conflictividad presente, anticipándose a los escenarios futuros.

A partir de la realidad local e insular de este territorio, parece pertinente que la construcción de un modelo de gobernanza exceda los límites de los enfoques monocéntricos y de la prevalencia de relaciones de arriba a abajo, desde lo gubernamental hacia la ciudadanía. Una alternativa emergente es la gobernanza policéntrica, que se refiere a la inclusión de múltiples actores y distintos niveles del Estado (Dorsch \& Flachsland, 2017). Se trata de la organización de redes descentralizadas que son conectadas a través de procesos de aprendizaje colaborativo. En la práctica, se orienta a crear sistemas adaptables que incluyan múltiples unidades de auto-gobierno de distintos niveles y escalas, capaces y dispuestas a interactuar y coordinarse por un objetivo común. Desde esta perspectiva, los sectores no estatales cobran mayor relevancia, (e.g., individuos y familias, municipios, el sector empresarial, ONG`s). La clave es la autoorganización y la coordinación de estas unidades en red sin relaciones jerárquicas, con un foco en temáticas o problemas locales que se abordan creando confianzas entre los actores.

No obstante se trata de una aproximación a la gobernanza que tiene a su vez un carácter adaptativo y multi-escalar que podría ser funcional a las características del contexto estudiado, se trata de un modelo que proviene de países desarrollados donde las relaciones sociales entre distintos actores son probablemente menos jerárquicas que en nuestro país. Si bien este tipo de gobernanza ofrece elementos a considerar, no parece pertinente omitir las dificultades asociadas a la desigual distribución del poder o la capacidad de influir en decisiones que tienen distintos grupos, lo cual es particularmente relevante en Chile y Latinoamérica. Por otra parte, tampoco existe clara evidencia de que un enfoque de abajo hacia arriba como éste, o que los gobiernos locales auto-organizados sean efectivamente más eficientes para enfrentar problemas ambientales. Sin embargo, la perspectiva policéntrica sugiere elementos que sí podrían ser considerados en futuros estudios e iniciativas en este contexto.

Finalmente, una pregunta clave es quién iniciará o debería iniciar un proceso de este tipo, considerando las percepciones sobre la participación ciudadana y sobre el rol de las comunidades en los temas presentados en este estudio. Probablemente la academia pueda facilitar iniciativas como ésta, considerando que en general es percibida como un actor válido, aunque distante, y que no tiene intereses económicos o políticos en este territorio. No obstante, se esperaría que una gobernanza local comenzase desde las organizaciones y comunidades que habitan este territorio, y que a partir de dicha movilización la academia pueda contribuir.

\section{CONCLUSIONES}

Este artículo buscó describir cómo actores clave de la Isla de Chiloé están percibiendo los problemas ambientales presentes en la Isla, particularmente el cambio climático, cómo están respondiendo a estos desafíos y de qué manera las condiciones de vida de la zona y los sistemas de creencia y valores de sus habitantes influencian 
la manera en que interactúan con el fenómeno $y$, por lo mismo, condicionan las posibilidades de enfrentarlo y de desarrollar un sistema de gobernanza climática adecuado.

A modo de síntesis, se puede plantear que el cambio climático es percibido como un problema emergente con impactos que ya están ocurriendo y cuyas consecuencias afectan tanto a los sistemas naturales como sociales de la Isla. Al mismo tiempo se constituye en un factor que incrementa la vulnerabilidad y conflictividad socioambiental ante el cual se despliegan respuestas generalmente individuales, externalizando las mayores responsabilidades para el desarrollo de soluciones más de fondo frente a estas problemáticas.

En general, las percepciones de los actores locales en Dalcahue respecto a los otros actores que confluyen en el territorio se encuentran bastante alineadas con la evidencia empírica disponible. Presentan un cuadro en que la perspectiva monocéntrica de la gobernanza no está funcionando, dado que imperan las asimetrías y competencia por sobre la colaboración, coordinación e intercambio de buenas prácticas entre los actores involucrados en el territorio. Todo esto refuerza la idea de que en el desarrollo de un sistema de gobernanza climática se deben abordar no sólo las limitaciones estructurales de la democracia chilena, sino también aquellas barreras psicológicas y estructurales que operan a nivel individual, comunitario y cultural.

Una de las limitaciones de este estudio fue la muestra, pues otros actores clave no pudieron ser considerados en esta oportunidad. Por ejemplo, grupos con altos índices de vulnerabilidad (e.g., comunidades indígenas, adultos mayores, mujeres), organizaciones ciudadanas y grupos ambientales más activos; como también representantes del sector privado y gubernamental. Esto obedeció a los recursos limitados disponibles y a que dada su complejidad, estos grupos demandan estudios más específicos, que esperamos puedan desarrollarse en un futuro cercano, y que profundicen tanto en un modelo de gobernanza aplicable a las características de estos territorios, como en las percepciones reportadas por este estudio. Futuras investigaciones podrían incorporar estudios cuantitativos para testear estas ideas en una muestra representativa de la Isla de Chiloé, diseños de investigación-acción participativa en distintas comunidades de la zona orientados a profundizar tanto las percepciones del cambio climático y de la gobernanza como así también las estrategias de adaptación que ya se están implementando. Finalmente, se sugiere establecer diálogos académicos que posibiliten el desarrollo de estudios comparativos con otras regiones dentro de Chile y fuera del país.

\section{AGRADECIMIENTOS}

Este trabajo ha sido financiado por CONICYT Chile como parte del Programa de Atracción e Inserción de Capital Humano Avanzado en el marco de la investigación: "Integrando el conocimiento psicológico y el estudio de las dinámicas sociales en el abordaje del cambio climático en Chile" (Folio 82140012). Se ha contado además con el patrocinio del Departamento de Psicología de la Universidad de Chile y del Centro de Ciencia del Clima y la Resiliencia (CR2). Agradecemos también a Adapt-Chile por la colaboración prestada en el marco del Fondo Canadiense para Iniciativas Locales (2016), proyecto realizado gracias a la Embajada de Canadá. Finalmente, damos las gracias al Departamento de Medio Ambiente del Municipio de Dalcahue, por su disposición a facilitar esta investigación.

\section{BIBLIOGRAFÍA}

Adger, N., Dessai, S., Goulden, M., Hulme, M., Lorenzoni, I., Nelson, D. R., Naess, L.,... \& Wreford, A. (2009). Are there social limits to adaptation to climate change? Climatic Change, 93(3-4) 335-354.

Aidt, T. (2003). Economic analysis of corruption: a survey. The Economic Journal, 113(491), 632-652.

Aitken, C., Chapman, R., \& McClure, J. (2011). Climate change, powerlessness and the commons dilemma: Assessing New Zealanders' preparedness to act. Global Environmental Change, 21, 752-760.

Alfaro, W., \& Ribera, L. (2008). Cambio climático en Mesoamérica: Temas para la creación de capacidades y la reducción de la vulnerabilidad. Consulta regional sobre prioridades, capacitación y retos de la investigación en cambio climático en los países de América Latina y el Caribe. Fundación Futuro Latinoamericano.

Andréu, J. (2000). Las técnicas de análisis de contenido: una 
revisión actualizada. Fundación Centro Estudios Andaluces, Universidad de Granada, 10(2), 1-34.

Ansell, C., \& Torfing, J. (2016). Handbook on theories of governance. Northampton: Edward Elgard.

Audefroy, J. (2015). Potential effects of climate change on the habitat in Mexico. Disaster Prevention and Management, 24(2), 249-262.

Bardin, L. (1996). Análisis de contenido. Madrid: Akal.

Barton, J., Román, A., Salazar, A., \& McPhee, B. (2013). ¿Son nuevas las ruralidades de Chiloé? Transformaciones territoriales y la "modernización" de los modos de vida rurales. En Anales de la Sociedad Chilena de Ciencias Geográficas, (pp. 197-203). Santiago de Chile: Sociedad Chilena de Ciencias Geográficas.

Biriescu, S., \& Babaita, C. (2014). Rural education, an important factor of regional development in the context of local government strategies. Procedia - Social and Behavioral Sciences, 124, 77-86.

Bustos-Gallardo, B. (2013). The ISA crisis in Los Lagos Chile: A failure of neoliberal environmental governance? Geoforum, 48, 196-206.

Carneiro, M. J., \& Da-Silva-Rosa, T. (2011). The use of scientific knowledge in the decision-making process of environmental public policies in Brazil. Journal of science communication, 10(1), 1-10.

Carreón, J., García, C., \& Morales, M. (2014). Hacia una administración consensuada de los recursos hídricos en ecociudades. Interdisciplinaria. Revista de Ciencias Sociales, 31(1), 163-174.

Chapin, F. S., \& Knapp, C. (2015). Sense of place: A process for identifying and negotiating potentially contested visions of sustainability. Environmental Science \& Policy, 53, 38-46.

Chapple, K., \& Montero, S. (2016). From learning to fragile governance: Regional economic development in rural Peru. Journal of Rural Studies, 44, 143-152.

Coffey, A. \& Atkinson, P. (2005). Encontrar el sentido a los datos cualitativos. Estrategias complementarias de investigación. Alicante: Publicaciones Universidad de Alicante.

CONAF \& UACH (2013). Informe Final de Monitoreo de cambios, corrección cartográfica y actualización del catastro de recursos vegetacionales nativos de la región de Los Lagos. Valdivia: CONAF.

Conde, A. C. (2008). Vulnerabilidad y adaptación al cambio climático: descripción de un estudio de caso y los retos en las investigaciones actuales. En J. Urbina \& J. Martínez (Eds.), Más allá del cambio climático. Las dimensiones psico-sociales del cambio ambiental global (pp. 157-171). México D.F.: UNAM.

De Dominicis, S., Fornara, F., Cancellieri, U. G., TwiggerRoss, C., \& Bonaiuto, M. (2015). We are at risk, and so what? Place attachment, environmental risk perceptions and preventive coping behaviours. Journal of Environmental Psychology, 43, 66-78.

DeWalt, K., \& DeWalt, B. (2002). Participant observation: a guide for fieldworkers. Walnut. Creek, CA: AltaMira Press.

Díaz, F. (2008). Guía práctica de terreno para realizar un manejo sustentable del pompón (Sphagnum magellanicum). Fundación Senda Darwin - Proyecto Fundación CopecUC TC026. http://www.sendadarwin.cl/espanol/wpcontent/uploads/2009/12/guia_de_terreno_ponpon. pdf. [16 de abril de 2010].

Dinda, S. (2004). Environmental Kuznets Curve Hypothesis: A Survey. Ecological Economics, 49(4), 431-455.

Dorsch, M., \& Flachsland, C. (2017). A Polycentric Approach to Global Climate Governance. Global Environmental Politics, 17(2), 45-64.

Espinosa, S. (2013). Variabilidad climática y adaptación social en Socoroma y Caquena: Una propuesta de educación ambiental. Santiago de Chile: Universidad de Chile.

Feo, O., Solano, E., \& Beingolea, L. (2009). Cambio climático y salud en la región andina. Revista Peruana de Medicina Experimental y Salud Pública, 26(1), 8393.

Flick, U. (2007). Introducción a la investigación cualitativa. Madrid: Morata.

Fløysand, A., Barton, J., \& Román, A. (2010). La doble jerarquía del desarrollo económico y gobierno local en Chile: El caso de la salmonicultura y los municipios chilotes. EURE, 36(108), 123-148.

Folchi, M. (2001). Conflictos de contenido ambiental y ecologismo de los pobres: no siempre pobres, ni siempre ecologistas. Ecología Política, 22, 79-100.

Folke, C., Hahn, T., Olsson, P., \& Norberg, J. (2005). Adaptive governance of social -ecological systems. Annual Review of Environment and Resources, 30, 441-473.

Forero, E., Hernández, Y., \& Zafra, C. (2014). Percepción latinoamericana de cambio climático: metodologías, herramientas $y$ estrategias de adaptación en comunidades locales. Una revisión. Revista U.D.C.A Actualidad \& Divulgación Científica, 17(1), 73-85.

Gaínza, A. (2006). La entrevista en profundidad individual. En M. Canales (Ed.), Metodología de investigación social (pp. 219-261). Santiago de Chile: LOM.

Gajardo, P., Mondaca, E., \& Santibáñez, P. (2016). La minería 
industrial como una nueva amenaza al espacio marino costero de Chiloé: Bahía de Cucao como caso de estudio. Archipiélago de Chiloé: Centro de Estudios Sociales de Chiloé / CESCH.

Gifford, R. (2011). The Dragons of Inaction Psychological Barriers That Limit Climate Change Mitigation and Adaptation. American Psychologist, 66(4), 290-302.

Greenpeace (2016). Reporte Crisis Social Ambiental en Chiloé Resumen Ejecutivo. http://www.greenpeace. org/chile/Global/chile/2016/9/informe_chiloe.pdf

Gupta, J. (2016). Climate change governance: history, future, and triple-loop learning? Wiley Interdisciplinary Reviews: Climate Change, 7(2), 192-210. doi: 10.1002/wcc.388.

Hardoy, J., \& Pandiella, G. (2009). Urban poverty and vulnerability to climate change in Latin America. Environment \& Urbanization, 21(1), 203-224.

Hardoy, J., \& Romero Lankao, P. (2011). Latin American cities and climate change: challenges and options to mitigation and adaptation responses. Current Opinion in Environmental Sustainability, 3, 158-163.

Harris, J., Reveco, C., \& Guerra, F. (2016). Gobernanza Climática y Respuestas Locales al Cambio Climático: Comparación de Estudios de Casos para Ciudades de la Alianza del Pacífico. Chile: Programa Regional Seguridad Energética y Cambio Climático en América Latina de la Fundación Konrad Adenauer. Adapt Chile. http://www.kas.de/wf/doc/kas_47138-1522-4-30. pdf?161121185619

Hernández, R, Fernández, C., \& Baptista, P. (1998). Metodología de la Investigación. México: McGrawHill Interamericana editores.

Hernández, J., Rodríguez, A. R., \& López-Hernández, E. (2015). Aspectos socioambientales para la adaptación y mitigación al cambio climático en comunidades de Nacajuca. Horizonte sanitario, 14(3), 87-95.

Infante, A., \& Infante, F. (2013). Percepciones y estrategias de los campesinos del secano para mitigar el deterioro ambiental y los efectos del cambio climático en Chile. Agroecología, 8(1), 71-78.

IPCC (2014). Climate Change 2014: Synthesis Report. Contribution of Working Groups I, II and III to the Fifth Assessment Report of the Intergovernmental Panel on Climate Change. Geneva, Switzerland: IPCC.

Islam, M. M., Sallu, S., Hubacek, K., \& Paavola, J. (2014). Limits and barriers to adaptation to climate variability and change in Bangladesh coastal fishing communities. Marine Policy, 43, 208-216.
Kaztman, R. (1999). Activos y estructuras de oportunidades. Estudios sobre las raices de la vulnerabilidad social en el Uruguay. Montevideo: Oficina del Programa de las Naciones Unidas para el Desarrollo/Oficina de CEPAL en Montevideo.

Kjaer, Anne Mette. (2004). Governance. Massachusetts, USA: Polity Press, Malden.

Kousky, C., \& Schneider, S. H. (2003). Global climate policy: will cities lead the way? Climate Policy, 3, 359-372.

Kooiman, J. (1993). Modern governance: new governmentsociety interactions. London, UK: Sage.

Lal, R. (2004). Soil carbon sequestration to mitigate climate change. Geoderma, 123, 1-22.

Leiserowitz, A. (2006). Climate change risk perception and policy preferences: the role of affect, imagery and values. Climatic Change, 77(1-2), 45-72

Leiserowitz, A., Maibach, E., Roser-Renouf, C., Feinberg, G., Rosenthal, S., \& Marlon, J. (2014). Climate Change in the American Mind: Americans' Global Warming Beliefs and Attitudes in November 2013. Yale University and George Mason University New Haven, CT: Yale Project on Climate Change Communication.

Leviston, Z., Price, J., Malkin, S., \& McCrea, R. (2014). Fourth annual survey of Australian attitudes to climate change: Interim report. Perth: Australia: CSIRO.

Lorenzoni, I., Nicholson-Coleb, S., \& Whitmarsh, L. (2007). Barriers Perceived to Engaging with Climate Change among the UK Public and their Policy implications. Global Environmental Change, 17, 445-459.

Marshall, C., \& Rossman, G. (1989). Designing qualitative research. Newbury Park, CA: Sage.

Mejía, J. (2000). El muestreo en la Investigación Cualitativa. Revista Investigaciones Sociales, 4(5), 165-180.

Merlinsky, G. (2006). La entrevista como forma de conocimiento y como texto negociado. Revista Cinta de Moebio, 27, 27-33.

Mitchell, T. (2006). Society, Economy and the State Effect. En A. Sharma \& A. Gupta (Eds.), The Anthropology of the State: A reader (pp. 169-186). Oxford: WileyBlackwell.

Moser, C. (1998). The asset vulnerability framework: Reassessing urban poverty reduction strategies. World Development, 1(26), 1-19.

Moser, S. C., \& Ekstrom, J. A. (2012). Identifying and Overcoming Barriers to Climate Change Adaptation in San Francisco Bay: Results from Case Studies. California Energy Commission. Publication number: CEC-500-2012-034.

Montaña, T. (2015). Gobernanza para el Cambio Climático. 
Estudio del caso gobierno local de MendozaArgentina. Argentina: Banco Interamericano de Desarrollo.

Montecinos, E. (2009). Plan Chiloé: De la actuación sectorialista a la gobernanza multinivel en la intervención territorial", documento de trabajo para el Programa Ciudadanía y Gestión Pública, inédito. Disponible en: http://www.subdere.gov.cl/sites/default/noticiasold/ articles-82969_recurso_21.pdf

Morrison, T. H. (2014). Developing a regional governance index: The institutional potential of rural regions". Journal of Rural Studies, 35, 101-111.

Mulyasari, I. G., Waluyati, L. R., \& Suryantini, A. (2018). Perceptions and local adaptation strategies to climate change of marine capture fishermen in Bengkulu Province, Indonesia. International Conference on Climate Change. IOP Conference Series: Earth and Environmental Science, 200(1), 012037.

Novión, C., \& Estrada, C. (2011). Percepción de los efectos vivenciales del cambio climático en una muestra de habitantes urbanos australes. Magallania (Punta Arenas), 39, 93-102.

Oficina de Cambio Climático, Ministerio del Medio Ambiente (2014). Plan nacional de adaptación al cambio climatico. Santiago, Chile: Ministerio del Medio Ambiente.

Otagri, B., Morales, E., \& Pardo, A. (2008). Las mujeres en Vera del departamento de Caldas, Colombia, frente a los efectos del cambio climático sobre su soberanía alimentaria. En A. Ulloa, E. Escobar, L. Donato \& P. Escobar (Eds.), Mujeres indigenas y cambio climático: Perspectivas Latinoamericanas (pp. 181194). Bogotá: UNAL-Fundación Natura de ColombiaUNODC.

Pérez, A. (2008). Mujeres indígenas de Guatemala y sus percepciones sobre el cambio climático. En A. Ulloa, E. Escobar, L. Donato \& P. Escobar (Eds.), Mujeres indígenas y cambio climático: Perspectivas Latinoamericanas (pp. 61-67). Bogotá: UNALFundación Natura de Colombia-UNODC.

Piñuel, J. L. (2002). Epistemología, metodología y técnicas del análisis de contenido. Estudios de Sociolingüística, 3 (1), 1-42.

Pizarro, R. (2001). La vulnerabilidad social y sus desafíos: una mirada desde América Latina. Santiago de Chile: CEPAL, División de Estadística y Proyecciones Económicas.

Pohlmann, A. (2011). Local Climate Change Governance. En A. Engels (Ed.), Global Transformations towards a
Low Carbon Society (p. 5). (Working Paper).

Quinn, T., Bousquet, F., Guerbois, C., Sougratu, E., \& Tabutaud, M. (2018). The dynamic relationship between sense of place and risk perception in landscapes mobility. Ecology and Society, 23(2), 39.

Quintero-Ángel, M., Carvajal-Escobar, Y., \& Aldunce, P. (2012). Adaptación a la variabilidad y el cambio climático: Intersecciones con la gestión del riesgo. Luna Azul, 34, 257-271.

RAMSAR. (2002). Lineamientos para la acción mundial sobre las turberas. Suiza: Secretaría de la Convención de Ramsar. http://www.ramsar.org/sites/default/files/ documents/pdf/guide/guide-peatlands-s.pdf

Renn, O. (2008). Risk Governance: Coping with Uncertainty in a Complex World. UK: Earthscan, Routledge.

Roco, L., Engler, A., Bravo-Ureta, B., \& Jara-Rojas, R. (2014). Farm level adaptation decisions to face climatic change and variability: Evidence from Central Chile. Environmental Science and Policy, 44, 86-96.

Roco, L., Engler, A., Bravo-Ureta, B. \& Jara-Rojas, R. (2015). Farmers' perception of climate change in mediterranean Chile. Regional Environmental Change, 15(5), 867879.

Rojas, J. (2012). Impactos sociales y ambientales del cambio climático global en la region del Bío Bio. Desafios para la sostenibilidad del siglo XXI. Concepción: Editorial Universidad de Concepción.

Rojas, J., \& Parra, O. (2010). Cambio climático local: la Región del Bío Bío en Chile en contexto global. Revista Brasileira de Ciências Ambientais, 17, 7-16.

Román, A., Barton, J., Bustos, B., \& Salazar, A. (2016). Revolución salmonera: paradojas y transformaciones territoriales en Chiloé. Santiago de Chile: Ril Editores.

Rubin, O., \& Rossing, T. (2012). National and local vulnerability to climate-related disasters in Latin America: The role of social asset-based adaptation. Bulletin of Latin American Research, 31(1), 19-35.

Sabatini, F. (1997). Conflictos ambientales y desarrollo sustentable de las regiones urbanas. Revista EURE Revista De Estudios Urbano Regionales, 23(68), 77 91.

Sapiains, R., Ugarte, A. M., \& Rdz-Navarro, K. (2017). Encuesta Nacional de Medio Ambiente y Cambio Climático. Santiago de Chile: Ministerio del Medio Ambiente.

Schensul, S., Schensul, J., \& LeCompte, M. (1999). Essential ethnographic methods: Observations, interviews, and questionnaires (Book 2 en Ethnographer's Toolkit). Walnut Creek, CA: AltaMira Press. 
Sepúlveda, Ma., Arismendi, I., Soto, D., Jara, F., \& Farías, F. (2013). Escaped farmed salmon and trout in Chile: incidence, impacts, and the need for an ecosystem view. Aquacult Environ Interact, 4, 273-283.

Shaffril, H. A. M., Samah, A. A., \& D'Silva, J. (2017a). Climate change: Social adaptation strategies for fishermen. Marine Policy, 81, 256-261.

Shaffril, H. A. M., Samah, A. A., \& D'Silva, J. (2017b). Adapting towards climate change impacts: Strategies for small-scale fishermen in Malaysia. Marine Policy, 81, 196-201.

Soares, D., \& Vargas, S. (2012). Capitales comunitarios y vulnerabilidad social frente al cambio climático. Trayectorias, 14(33-34), 51-76.

Stedman, R. (2016). Subjectivity and socialecological systems: a rigidity trap (and sense of place as a way out). Sustainability Science, 11(6), 891-901.

Sterman, J. (2011). Communicating climate change risks in a skeptical world. Climatic Change, 108(4), 811.

Sterman, J., \& Booth-Sweeney, L. (2007). Understanding public complacency about climate change: adults' mental models of climate change violate conservation of matter. Climatic Change, 80(3-4), 213-238.

Taylor, S., \& Bogdan, R. (1994). Introducción a los métodos cualitativos de investigación. Barcelona: Paidós.

Termeer, C. J. A. M., \& Dewulf, Art \& Lieshout, Maartje. (2010). Disentangling Scale Approaches in Governance Research: Comparing Monocentric, Multilevel, and Adaptive Governance. Ecology and Society 15, 4. 15. 10.5751/ES-03798-150429.

Torfing, J., Peters, G., Pierre, J., \& Sørensen, E. (2012). Interactive Governance: Advancing the Paradigm. Oxford: Oxford University Press.

Transparency International (2017). Corruption Perceptions Index 2016. [en línea]. https://www.transparency.org/ news/feature/corruption_perceptions_index_2016

Tucca, F., Moya, H., Pozi, K., Borghini, F., Focardi, S., \& Barra, R. (2016). Occurrence of antiparasitic pesticides in sediments near salmon farms in the northern Chilean
Patagonia. Marine Pollution Bulletin, 15, 465-468.

Ulloa, A. (2008). Mujeres indígenas y cambio climático. Perspectivas Latinoamericanas. Introducción. En A. Ulloa, E. Escobar, L. Donato \& P. Escobar (Eds.), Mujeres indígenas y cambio climático: Perspectivas Latinoamericanas (pp. 15-34). Bogotá: UNALFundación Natura de Colombia-UNODC.

Universidad de Los Lagos. 2016. Informe final Comisión Marea Roja. http://www.economia.gob.cl/ wp-content/uploads/2016/11/InfoFinal_ ComisionMareaRoja_24Nov2016-1.compressed.pdf

Vargas, J. (2002). Políticas Públicas para la reducción de la vulnerabilidad frente a los desastres naturales y socionaturales. Santiago de Chile: CEPAL.

Vial, C. (2016). Las Municipalidades en Chile. En J. Ruano, \& C. Vial (2016). Manual de Gobiernos locales en Iberoamérica (pp. 111-137). Santiago: Centro Latinoamericano de Administración para el Desarrollo (CLAD), Universidad Autónoma.

Wilches-Chaux, G. (2000). En el borde del caos. Pensar, Instituto de Estudios Sociales y Culturales. Colombia: Pensar, Instituto de Estudios Sociales y Culturales, Universidad Javariana.

Williams, S., \& Schaefer, A. (2013). Small and Medium-Sized Enterprises and Sustainability: Managers' Values and Engagement with Environmental and Climate Change Issues. Business Strategy and the Environment, 22, 173-186

Yana, O. (2008). Diferencias de género en las percepciones sobre indicadores climáticos y el impacto de riesgos climáticos en el altiplano Boliviano: Estudio de caso en los municipios de Umala y Ancoraimes, departamento de La Paz. En A. Ulloa, E. Escobar, L. Donato \& P. Escobar (Eds.), Mujeres indígenas y cambio climático: Perspectivas Latinoamericanas (pp. 43-54). Bogotá: UNAL-Fundación Natura de Colombia-UNODC.

Young, G., Zavala, H. ,Wandel, J., Smith, B., Salas, S., Jiménez, E., Fiebig, M.,... \& Cepeda, J. (2010). Vulnerability and adaptation in a dryland community of the Elqui Valley, Chile. Climatic Change, 98(1-2), 245-276. 